\title{
EL SISTEMA ELECTORAL Y DE PARTIDOS EN EUZKADI
}

\author{
Ramito Cibrián \\ (Universidad Complutense de Madrid)
}

Ofrece este ensayo un análisis del comportamiento electoral en Euzkadi, en el que se incluye, a efectos comparativos, la provincia de Navarra, tomando como base los resultados de las elecciones legislativas de 1977 y de 1979, así como una referencia a las elecciones de los años treinta. Se diferencian dos dimensiones fundamentales: los datos electorales y el sistema de partidos que se va configurando en Euzkadi. El presente trabajo se divide en tres partes: a) el estudio de las pautas electorales manifestadas en las diferentes circunscripciones con la intención de detectar las regularidades producidas; b) la câracterización del sistema de partidos vasco mediante la aplicación de parámetros, como puede ser el índice de volatilidad del voto; y c) el análisis de las correlaciones existentes entre los resultados obtenidos por los cuatro partidos «polares» del espacio bidimensional propuesto como modelo, determinado por las componentes izquierda-derecha y nacionalismo-centralismo. 


\section{Introducción}

Este trabajo está dedicado al análisis de los datos electorales de 1977 y 1979, y del sistema de partidos que como resultado de los mismos se configuran en Euzkadi. Se incluye en este término a las provincias de Alava, Guipúzcoa, Navarra y Vizcaya. Se trata de un enfoque taxonómico, que no pretende entrar en discusiones sobre si Navatra o las provincias vascofrancesas deberían o no considerarse en el estudio. Navarra se incluye porque se dispone de datos para hacerlo, porque las elecciones allí son simultáneas y de la misma naturaleza que las que se celebran en las otras tres provincias, y porque, en una medida muy significativa, los partidos que compiten en las cuatro provincias son los mismos (aunque en el caso de Navarta suelan algunos cambiar de siglas). Precisamente por las razones contrarias no se pueden incluir en el estudio a Lapurdi, Zuberoa y Benavarra. ${ }^{1}$

Los datos utilizados corresponden sobre todo a las elecciones de 1977 , para las que se disponen de resultados a nivel municipal. Se han utilizado también los resultados provisionales provinciales de las legislativas de 1979 , ya que en ellas se han producido cambios importantes en el mapa electoral, y el prescindir de estas elecciones desfasaría y restaría capacidad explicativa al trabajo. ${ }^{2}$ Además, se puede decir que la inclusión de los resultados de

1. Los partidos más decididamente contrarios a la integración de Navarra en la comunidad autonómica vasca han consolidado (UCD) o mejorado (UPN) en las legisLativas de 1979 sus votos de 1977, mientras que las dos coaliciones más claramente integracionistas no alcanzaban el $17 \%$ de los votos. Se insiste, no obstante, en que el fin del estudio es conocer la sociología electoral y el sistema de partidos vasco allí donde compiten y con independencia de que los partidos racionalistas vascos sean más débiles o más fuertes. Los estudios de sociología electoral española suelen incluir a Guipúzcoa, Vizcaya y Barcelona, a pesar de que en estas provincias los partidos espa. toles son más débiles que en el resto de España.

2. Los datos de 1977 proceden del listado de ordenador desglosado a nivel mu. nicipal, que fue entregado por el Ministerio del Interior a los partidos a efectos de subvenciones. (Como se sabe, no existen resultados oficiales definitivos de estas elec- 
1979 sirve para interpretar mejor ciertos aspectos de las elecciones anteriores.

El trabajo consta de tres partes. En la primera se presentan las pautas electorales, haciendo una comparación histórica con los resultados globales de las elecciones de los años treinta, y una comparación más detallada a nivel provincial entre los resultados de las dos últimas elecciones. Para este análisis se agrupan los porcentajes de votos obtenidos por partidos o coaliciones en grandes bloques o tendencias, pues, además de facilitat la interpretación de los mismos, resulta imprescindible hacerlo por no disponerse de datos electorales de la Segunda República desagregados a nivel de partidos o coaliciones. ${ }^{3}$

La segunda parte incluye una exposición de los principales paráme. tros del sistema de partidos identificados por D. Rae, y estimados por medio de los datos de 1977. Para la caracterización del sistema de partidos vasco de acuerdo a la tipología de $G$. Sartori, se utiliza un gráfico bidimensional, construido en parte de acuerdo con los resultados electorales de 1979 , y en parte también en base a hipótesis plausibles sobre la ubicación de los partidos políticos sobre el mismo.

La tercera y última parte presenta cierta evidencia, en forma de coeficientes de correlación entre cuatro partidos, a favor del sistema de partidos propuesto. Aunque el alcance de estos coeficientes no puede ser sobreestimado (entre otros por el problema de la falacia ecológica) no obstante pueden suministrar información sobre la distribución ecológica para una provincia dada, de los electorados de los partidos en cuestión. Esta distribución geográfica puede reforzar o rechazar las hipótesis establecidas sobre esos partidos y sus correspondientes electorados.

\section{La evolución electoral de los bloques politicos}

Los resultados obtenidos en las elecciones de 1977 por los partidos de izquierdas y de detechas, están en España correlacionados a nivel provincial con los resultados obtenidos en las elecciones de 1936 por las iz.

ciones.) Los datos de 1979 se han tornado de las ediciones de los periódicos «Deia» y «Egin» del 3 de marzo, y son, por tanto, provisionales.

3. Corno es sabido, el sistema electoral de la Segunda República se basaba en listas abiertas, con una fórmula electoral de tipo semimayoritario. Véase J. M. de Miguel y J. J. Linz, Hacia un análisis regional de las elecciones de 1936 en España, «Revista Española de la Opínión Públicam, 48 (junio 1977): pp. 27.68; en donde se puede encontrar la única estimación conocida de los posibles porcentajes de votos para los diferentes partidos y coaliciones que participaron en las elecciones de dicho año. 
quierdas (el Ftente Popular) y las derechas. ${ }^{4}$ Los tesultados de 1979 han repetido en gran medida los porcentajes de votos que habían sido obtenidos en 1977 por los principales partidos que compiten en toda España. Se puede por tanto afirmar que el sistema electoral español responde en medida significativa al modelo de sistema electoral de tipo «viscoso» o «congelado», en el cual la tratısferencia de cantidades importantes de votantes de unas opciones a otras o la emergencia o desaparición de las principales fuerzas electorales, ocure con lentitud y dificultad. ${ }^{5}$

El mapa electoral que se configura en Euzkadi en las primeras elecciones postfranquistas, presenta también, tanto at nivel nacional vasco como en cada una de las cuatro provincias, pautas similares a las que se manifestaron durante los años treinta. Esta afirmación no se refiere a partidos políticos concretos (aunque la distribución geográfica de la implantación del PNV y del PSOE ha variado telativamente poco en los últimos cuarenta años), sino que se basá más bien en los porcentajes de votos obtenidos al agrupar a los partidos de ayer y de hoy en los cuatro grandes bloques o tendencias que resultan de las escisiones izquierda/derecha y nacionalista/no nacionalista. ${ }^{6}$ Esto es lo que se ha hecho en la Tabla 1, en la que aparecen los resultados por bloques para las últimas cinco elecciones al Congreso de Diputados español celebradas en Euzkadi.

Uno de los comentatios más importantes de los datos de la Tabla 1 se refiere al nivel de participación. Éste, durante los años treinta, estaba siempte por encina de la media española, la cual solía situarse alrededor

4. En el trabajo de D. Vila, F. Andrés Orizo y M. Gómez Reino, Sociología del actual cambio politico en España, «I II Informe FOESSA» (Madrid: Euramérica, 1978), pp. 716.717, se incluyen los coeficientes de correlación entre los cuatro primeros partidos españoles en 1977 y los resuliados estimados de 1936. Las cotrelaciones PSOE (1977) / PSOE (1936) y PCE (1977) / Frente Popular (1936) son altas y positivas. Y lo mismo ocurre para las correspondientes correlaciones entre la derecha.

5. La tesis de la "congelación» de los sistemas de partidos europeos fue inicialmente formulada por S. M. Lipset y S. Rokkan, en Party System and Voter Alignments (Nueva York: Free Press, 1967). En el trabajo de M. D. Pedersen, The changing European party system: Patterns of dectoral volatility, IX. Congreso Mundial de Sociología (Upsała, 1978), se incluye unel tecapitulación de las diversas posiciones mantenidas sobre la tesis y un excelente tstudio empírico usando los datos de la posguerra y una nueva variable, la «volatilidad», como instrumento para medir los cambios en los sistemas de pattidos.

6. Véase la Tabla del Apéndice para un listado de las fuerzas políticas vascas contemporáneas y su correspondientt: adscripción a una de las cuatro posibles tendencias políticas que aqui se utilizan; Jerecha-española, derecha-nacionalista, izquierda-no nacionalista e izquierda-abertzale o racionalista. Una clasificación de las fuerzas vascas contemporáneas, según criterios algo diferentes, puede encontrarse en el estudio de L. C. Núñez, La sociedad vasca aciual (San Sebastián: Txertoa, 978), cap. 8, en el que se analizan Ios xesultados electorales de 1977. 
«Papers»: Revista de Sociologia

\section{TABLA 1}

Resultados por bloques de las elecciones al Congreso en Euzkadi

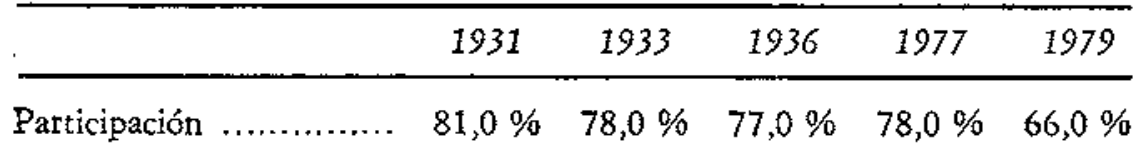

Derecha española

$\begin{array}{lllccc}\text { \% votos } \ldots \ldots \ldots \ldots \ldots . & 32,9 & 39,0 & 43,0 & 28,7 & 26,0 \\ \text { Escaños } \ldots \ldots \ldots \ldots \ldots . . & 8 & 10 & 8 & 8 & 9 \\ \text { \% escaños } \ldots \ldots \ldots \ldots \ldots & 33,0 & 42,0 & 33,0 & 31,0 & 35,0\end{array}$

Derecha nacionalista

$\begin{array}{lllccc}\% \text { votos } \ldots \ldots \ldots \ldots \ldots . & 30,6 & 35,0 & 28,0 & 24,3 & 23,0 \\ \text { Escaños } \ldots \ldots \ldots \ldots \ldots . . & 7 & 12 & 9 & 8 & 7 \\ \% \text { escaños } \ldots \ldots \ldots \ldots . . & 29,0 & 50,0 & 38,0 & 31,0 & 27,0\end{array}$

Izquierda

$\begin{array}{cccccc}\text { \% votos } \ldots \ldots \ldots \ldots \ldots & 36,4 & 26,0 & 30,0 & 36,7 & 29,0 \\ \text { Escaños …........... } & 9 & 2 & 7 & 9 & 6 \\ \% \text { escaños } \ldots \ldots \ldots \ldots \ldots & 38,0 & 8,0 & 29,0 & 35,0 & 23,0\end{array}$

Izquierda abertzale

$\begin{array}{llllll}\% \text { votos } \ldots \ldots \ldots \ldots \ldots & - & - & - & 10,3 & 20,0 \\ \text { Escaños } \ldots \ldots \ldots \ldots \ldots . & - & - & - & 1 & 4 \\ \% \text { escafios } \ldots \ldots \ldots \ldots . & - & - & - & 4,0 & 15,0 \\ & & & & & \\ & 10,5 \% & 7,5 \% & 17,5 \% & 11,7 \%\end{array}$

Euentes: Los resultados de los años treinta proceden de J. Tussell y G. Garcfa, wIntrodacción a una sociolog fa electoral đel Pás Vasco durante la If Repúblicas. Madrid: Manuscrito mimeografiado, s.f., i S. Payne, Et nacionalismo vasco: De sus orfgenes a ETA, 3a. ed. (Barcelona: Dopesa, 2974).

del $65 \%{ }^{7}$ En los años setenta la participación vasca, por el contrario, es sustancialmente similar a la media estatal. Aunque en las elecciones de 1977 este hecho estuvo parcialmente ocasionado por la abstención militante propugnada por el KAS (HASI, LAIA, ETA-m), la cual tuvo una cierta inci-

7. Los datos sobre las elecciones de los años treinta en Euzkadi proceden de J. Tussell y G. García: Introducción a una sociología electoral del País Vasco durante 
dencia en las provincias costeras, en 1979 las causas tienen que ser distintas, ya que toda la izquierda abertzale participa activamente en las últimas elecciones. Sólo como hipótesis se puede adelantar que la abstención de 1979 proceda básicamente de los sectores de izquierdas y de derechas no nacionalistas, como resultado del clima de polarización y violencia de los últimos tiempos.

Otro dato significativo es la ausencia durante los años treinta de una izquierda abertzale con entidad. El partido ANV nunca tuvo importancia electoral fuera de Bilbao, y participó en coaliciones con otras fuetzas (en 1933 con el PNV y en 1936 con el Frente Popular). La izquierda abertzale es ahora el nuevo bloque de la política vasca, que se fragua y cristaliza durante el franquismo, como consecuencia directa de la lucha armada de ETA. La emergencia electoral de este bloque en las elecciones de 1977 estuvo dificultada, en parte, por la abstención cirada de sus sectores más radicales, y en parte porque la campaña, y sobre todo la precampaña electoral de 1977 se llevó a cabo sin que existiesen unas plenas condiciones democráticas. En aquellas condiciones los partidos de izquierda abertzale que participaron (EIA, ESB, ANV) obtuvieron en Euzkadi un ya significativo $10 \%$ de los votos, que se duplicó en 1979 al participar este bloque agrupado en torno a dos únicas coaliciones electorales: $\mathrm{HB}$ (KAS, HASI, LAIA, ESB, ANV, GPA, e independientes) y EE (EIA, en coalición con el partido de la izquierda no nacionalista PTE, e independientes).

La izquierda abertzale es un bloque con un gran dinamismo interno, y en fase expansiva. A pesar de ello, hoy por hoy y para el conjunto de Euzkadi, es en términos electorales el más débil de los cuatro bloques que se usan en este análisis del voto vasco. Los otros tres bloques han sido, y continúan siendo, de una fuerza aproximadamente similar los unos a los otros. Esto, que no es cierto a nivel provincial, resulta bastante aproximado para todo el País Vasco. En términos de número de diputados, las diferencias entre estos tres bloques «históricos» vienen a oscilar de uno a dos escaños. Una excepción importante a esta tónica ocurre en 1933 con la izquierda no nacionalista (entonces constituida fundamentalmente por socialistas y republicanos) que experimenta una importante pérdida de diputados, de 9 a 2, debido tanto a la tendencia general derechista de la elección, como a la decisión del PSOE de acudir a la misma sin formar ningún

\footnotetext{
la Segunda República (Madrid: manuscrito mineografiado, s.f.), y de S. Payne: El nacionalismo vasco: De stus orígenes a ETA (Barcelona: Dopesa, 1974). En estos trabajos se contienen datos sobre las consultas referentes a los estatutos de autonomía, elecciones locales, etc, además de detalles sobre las diversas vueltas de las elecciones legislativas. Los datos aquí utilizados son siempre los de la primeza vuelta.
} 
tipo de coaliciones. ${ }^{8}$ En la primeta elección de los años setenta la izquierda no nacionalista consigue unos resultados tan buenos como los de 1931, tanto en términos de porcentajes como de escaños, pero en 1979, al igual que en las primeras elecciones legislativas de la Segunda República, pierde parte importante del terreno avanzado en las Constituyentes.

El bloque de derecha española (carlista y CEDA en los treinta; UCD y AP-CD ahora) ha sufrido un retroceso apreciable en cuanto a los porcentajes de votos que solía obtener en la República. Su porcentaje medio para los años treinta era de aproximadamente un $38 \%$, mientras que en las dos elecciones de los setenta obtiene de media alrededor del $27 \%$. Este retroceso en votos no se ha manifestado demasiado en escaños, debido a que la mayor fuerza electoral de este bloque se centra precisamente en las dos provincias interiores, las cuales están sobrerrepresentadas, y en las cuales, al haber pocos escaños para repartir (4 en Alava y 5 en Navarra) el sistema de Hondt viene a actuar en la práctica como un sistema semimayotitario. De los 8 escaños obtenidos por este bloque en 1977, 5 lo fueron en las provincias interiores, y en 1979 esta proporción fue 6 de 9 . En escaños totales, el porcentaje que obtiene este bloque se sitúa consistentemente alrededor de un $33 \%$ para todo el período estudiado.

El hablat de un bloque de derecha nacionalista es lo más inadecuado del presente análisis, ya que nos encontramos aquí con un bloque monopartidista. El PNV es el único partido que ocupa esta zona del espectro político bidimensional que se está usando como referencia y criterio de clasificación. En términos de votos la derecha nacionalista, al igual que la española, también ha visto decrecer su porcentaje con respecto al de los años treinta. Su media entonces oscilaba sobre un $31 \%$, mientras que ahora se centra alrededor de tn $24 \%$. En la distribución de escaños el PNV también se suele beneficiar, al tener su electorado concentrado en las dos provincias costeras. Pero al menos durante los años setenta este beneficio procede exclusivamente de las ventajas que el sistema de Hondt pueda dar al partido con una mayoría relativa, ya que estas provincias costeras están infrarrepresentadas en la distribución de escaños, tanto con respecto a las otras dos, como con respecto a la media española. En cualquier caso el PNV siempre ha obtenido un mínimo de 7 sobre los 24 (Segunda República) o 26 (Monarquía Constitucional) escaños que corresponden al País Vasco.

8. La ley electoral de 1931, al igual que la de 1977, favorecía la formación de coaliciones y penalizaba a las tendencias cuyo voto está fragmentado. La izquierda abertzale, y en particular los partidos integrantes de $\mathrm{HB}$, parecen ser los únicos que hasta la fecha están dispuestos a beneficiarse de las ventajas que reporta a las coaliciones la actual ley. 
La izquierda no nacionalista es el bloque que tradicionalmente aparece más fragmentado de cara a las elecciones. lésta suele ser una de las causas de que sus porcentajes de escaños suelan ser inferiores a los de votos. El porcentaje medio para este bloque durante los años treinta se sitúa en un $31 \%$ de los votos. Éste es el único de los bloques históricos que reaparece en 1977 con un porcentaje de votantes sensiblemente superior a su media de los años treinta, alcanzando un máximo histórico del $36,7 \%$. Sin embargo, las elecciones de 1979 le suponen una pérdida de casi un $8 \%$ de los votos, y 3 de los 9 diputados obtenidos en 1977.

Aunque es ciertamente probable que la emergencia de la izquierda abertzale se esté llevando a cabo a costa de los dos bloques de los cuales pretende ser la síntesis, es decir, del nacionalismo de derechas, y de la izquierda no nacionalista $-\mathrm{y}$ en términos de ideología, militantes, cuadros, dirigentes, e incluso votantes esto seguramente ej así-, cuando se estudian las series históricas electorales la izquierda no nacionalista es el bloque que menos pierde con respecto a los años treinta. En este sentido se puede decir que la irrupción electoral de la izquierda abertzale en la política electoral vasca se está produciendo hasta ahora a costa sobre todo de los dos bloques de derechas.

Como se ha apuntado, Ja implantación relativa de los cuatro bloques no es homogénea a través de las provincias vascas. Esto se pone de manifiesto en la Tabla 2, en la que aparecen los resultados de las dos últimas elecciones desagregados a nivel provinciai. Se puede observar que en 1977 los niveles de participación en las dos provincias interiores fueron signiffcativamente superiores a los de las costeras, situándose incluso por encima de la media española, que fue del 78,4\%. Esta diferencia está relacionada con el hecho de que la izquierda abertzale que propugnó la abstención, es mucho más fuerte en Guipúzcoa y Vizcaya que en las otras dos provincias. ${ }^{9}$ En 1979 las diferencias de participación entre las cuatro provincias no son ya $\tan$ acentuadas, aunque el número de abstenciones en Navarra es toda. vía cinco o seis puntos inferior al de las otras provincias. Alava, por el contrario, experimenta en 1979, en éste y en otros detalles, una aproximación mucho mayor a las pautas electorales de Guipúzcon y Vizcaya.

Alava, y sobre todo Navarra, son las provincias en las que los partidos de derecha española son más fuertes. En la segunda de estas provin-

9. Como lo demutestran Ios resultados obtenidos por HB en 1979. En esta coalición se integra prácticamente toda la izquierda abertzale abstencionista en 1977. No existen aún trabajos acadérnicos sobre la izquierda abertzale. Puede extraerse informacion de Ortzi, Historia de Euzkadi: El nacionalismo vasco y la ETA (París: Ruedo Ibético, 1975); y del folleto de I. Estornés, ¿Quế son los partidos abertzales? (San Sebastián: I. Estornés, 1977). 


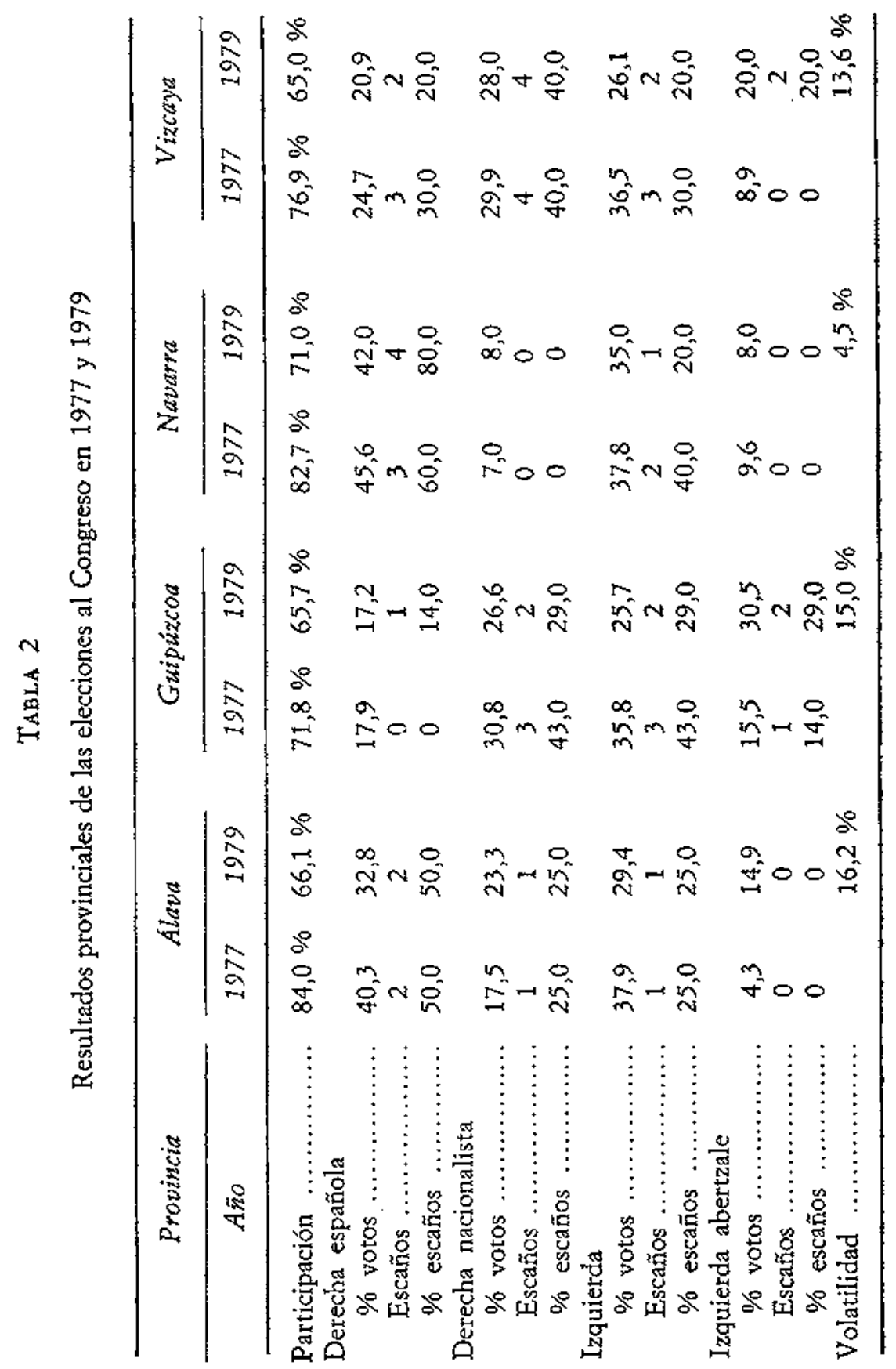


cias estos partidos han superado el $40 \%$ de los votos en las dos elecciones últimas. A pesar de disminuir su porcentaje de votos ligeramente en 1979, incrementaron sus escaños de tres a cuatro, gracias al que gana UPN a costa del PSOE. En Alava el bloque sufre un tetroceso del 7,5\% entre las dos elecciones, pero conservan sus dos diputados. En Vizcaya ei porcentaje de votos perdidos ha sido pequeño, del $3,8 \%$. UCD ha conservado sus dos diputados en esta provincia y $C D$ ha perdido el obtenido por AP en 1977. En Guipúzcoa el porcentaje de votos se ha mantenido prácticamente constante, pero ha estado mucho más concentrado alrededor de UCD, partido que no concurrió en esta provincia en las elecciones de 1977. Entonces el voto de derecha española estuvo repartido entre tres candidaturas diferentes (GU-AP $8,1 \%$, DCV 5,0\%, DIV 4,6\%) lo que les impidió lograr algún diputado. En 1979 la concentración de este voto en la lista de UCD ha proporcionado a este partido su primet escaño en la provincia.

La derecha nacionalista siempre ha tenido sus feudos en Vizcaya $y$ Guipúzcoa. Su implantación en Álava ha sido y es comparativamente menor, centrada sobre todo en los municipios del norte de la provincia y las capas medias autóctonas de la capital. En Navarra la implantación de este bloque continúa siendo la más débil de las cuatto provincias. En las provincias costeras el PNV ha experimentado en la última elección unas pérdidas moderadas. En Guipúzcoa ha perdido el único diputado de los ocho que obtuvo en 1977 en toda Euzkadi. ${ }^{10} \mathrm{El}$ éxito más notable del partido en 1979 se encuentra en los resultados de Alava, en donde pasa del 17,5\% al $23 \%$ de los votos, acercándose al resuitaclo de UCD, que en 1977 había sido con clara ventaja el primer partido de la provincia. La debilidad del PNV en Navarra le ha inducido a presentarse allí en coaliciones con otros partidos, a pesar de lo cual las mismas no han superado el $8 \%$ de los votos. En 1977 formó con ESB y ANV, partidos socialdemócratas de la izquierda abertzale, la coalición UAN, que obtuvo el $7 \%$ de los votos. En 1979 integró una coalición unás heterogénea con EIA y el PTE, obteniendo el $8 \%$. Al igual que en Álava la fuerza del voto nacionalista de derechas está muy concentrada en los municipios del notoeste de la provincia limítrofes con Guipúzcoa, mientras que en el resto de Navarra, incluida la capital, su potencialidad electoral es mucho más limitada. ${ }^{11}$

10. En 1977 el PNV obtuvo cuatro escaños en Vizcaya, tres en Guipúzcoa y uno en Alava. La clasifficación que aquí se hace de la DCV como uns fuerza de derecho espaüola se basa más en la posición de su electorado que en la de alguno de sus lideres, a veces próximos al PNV.

11. La concentración del voto PNV en Alava y Navarta en las zonas de estas provincias limitrofes con las dos costeras queda puesta de relieve con gran nitidez en mapas electorales municipales. Un equipo de investigadores dirigido por J. I. Cases. 
Lo más característico del voto de izquierda no nacionalista es que se trata del voto que está más homogéneamente distribuido entre las cuatro provincias. Esto fue particularmente cierto en 1977, pues entonces los límites de variación fueron el máximo del $37,9 \%$ en Álava, y el mínimo del 35,8\% en Guipúzcoa. En 1979 el conjunto de los votos de esta tendencia ha disminuido alrededor del $8 \%$ al $10 \%$ en todas tas provincias salvo en Navarra, en donde el decrecimiento ha sido sólo de un $3 \%$. Los problemas de fraccionalización interna (pues se trata sin duda del bloque en el que se encuadran el mayor número de partidos), suelen reflejarse en importantes pérdidas de escaños en cuanto disminuyen los votos. El PSOE, que es con distancia la fuetza principal del bloque, ha perdido en 1979 un escaño en cada una de las provincias de Guipúzcoa, Vizcaya y Navarta. ${ }^{\text {.2 }}$ Conviene mencionar que aunque el voto de izquierda no nacionalista está uniformemente repartido entre las cuatro provincias, presenta, sin embargo, importantes variaciones dentro del interior de cualquiera de ellas, pues en general este tipo de voto está centrado alrededor de las capitales y los pueblos y ciudades industriales en los que viven los obreros inmigrantes procedentes de otras partes de Espafia.

Las pautas del voto de la izquierda abertzale siguen en cierta medida las del PNV. La provincia con una mayor proporción de votos de izquierda abertzale es Guipúzcoa, tanto en las elecciones de 1977, como en las de 1979. En estas últimas elecciones el porcentaje de este bloque en la citada provincia se incrementa desde un $15,5 \%$ hasta el $30,5 \%$, con lo que viene a convertirse en el primero de los cuatro bloques alle. Este importante porcentaje se traduce solamente en dos diputados (uno de HB y otro de $\mathrm{EE}$ ) debido a la división del voto entre estas dos coaliciones. La izquierda abertzale también está bien implantada en Vizcaya, en donde pasa del $8,9 \%$ al $20 \%$ de los votos. Pero en esta provincia cualquiera de los otros tres bloques está por delante de ella, si bien la diferencia con la derecha española es mínima. Al igual que en el caso del PNV los tesultados de Alava en 1979 han mostrado un importante incremento, habiéndose multiplicado su porcentaje por un factor de casi 3,5. Los resultados de $\mathrm{Na}$. varra siguen siendo los más discretos. En esta provincia $\mathrm{HB}$ obtuvo el $8,0 \%$ de los votos, a los que habría que sumar los de ETA-EE que se unieron a los del PNV en la coalición Nacionalistas Vascos, y que en este análisis han

de la Facultad de Ciencias Polf́ticas y Saciología de la Universidad Complutense, está Ilevando a cabo un exhaustivo estudio sobre las elecciones de 1977 que incluye la confección de estos mapas en todas las provincias de España para los principales partidos.

12. Todos los escaños obtenidos en 1977 y 1979 por la izquierda no nacionalista corresponden at PSOE. 
sido asignados globalmente a la derecha nacionalista. El retroceso que reflejan los resultados de Navarra puede ser aparente, además de por la razón citada, porque en 1977 el voto de izquierda abertzale se ha identificado con el voto de UNAI. Esta última se trataba de una coalición organizada por el EMK (entonces miembro de EE en las otras tres provincias) en torno a independientes de prestigio. Posiblemente no todos los votos que en 1977 recibió UNAI fueron de abertzales de izquierda.

En las Tablas 1 y 2 se han incluido estimaciones preliminares de la volatilidad electoral, calculadas piria los datos agrupados en bloques. ${ }^{13} \mathrm{La}$ volatilidad entre las elecciones del año 1979 y 1977, por ejemplo, es igual a un medio de la suma de los valores absolutos de las diferencias entre el porcentaje de votos obtenidos en el año 1979 y el obtenido en 1977. Esta suma se extiende a todos los partidos o coaliciones que intervienen en uno cualquieta de los años, o en los dos. En el primer caso se les da un $0 \%$ para el año en que no participan. La volatilidad es una medida de lo que cambia el sistema de partidos de una elección a otra. Aunque las Tablas 1 y 2 expresan la volatilidad referida a bloques, la cual es inferior a la que resultaría de usar partidos y coaliciones, permiten, sin embargo, concluir que, en primera aproximación, la volatilidad electoral reciente del País Vasco es elevada, y en cualquier caso superior a las medias española y de otros países europeos.

La volatilidad para España entre las elecciones de 1977 y 1979, estará situada posiblemente alrededor del $9 \%-10 \%$, mientras que todas las provincias vascas, excepto Navarra, superan simplemente por medio de la más baja volatilidad de bloques, esta cifra. Pata tener idea de lo que representan estas cifras se puede citar que, de acuerdo con los datos de M. D. Pedersen, la volatilidad media de las elecciones en 13 democracias europeas durante el período 1948-1977 fue del 8,1\%, siendo Austria con el 3,7\% y Francia con el $16,8 \%$ los casos extremos de volatilidad media por elección. ${ }^{14}$ En Portugal la volatilidad media entre las dos primeras elecciones libres postsalazaristas se puede estimar airededor del $15 \%$.

Así pues, mientras que el sistema de partidos español aparece relatin vamente viscoso y congelado, máxime teniendo en cuenta que está en pe-

13. Para una definición matemática de la variable volatilidad, véase $M$. P. Pedersen, obra citada, p. 11. De la Tabla 1 se deduce que el sistema de partidos vasco tendia a ser más viscoso en los años treinta que en nuestros dias.

14. M. D. Pedersen, obra citada, Tabla 1, p. 17. Los países estudiados son, además de Austria y Francia, y en orden de volatilidad creciente, Suiza, Suecia, Reino Unido, Finlandia, Bélgica, Irlanda, Noruega, Italia, Holanda, Alemania Federal y Dinamaxca. La tesis de Pedersen es que los países nórdicos hat experimentado en las últimas elecciones fuertes incrementos de la volatilidad, salvo quizás en Suecia. 


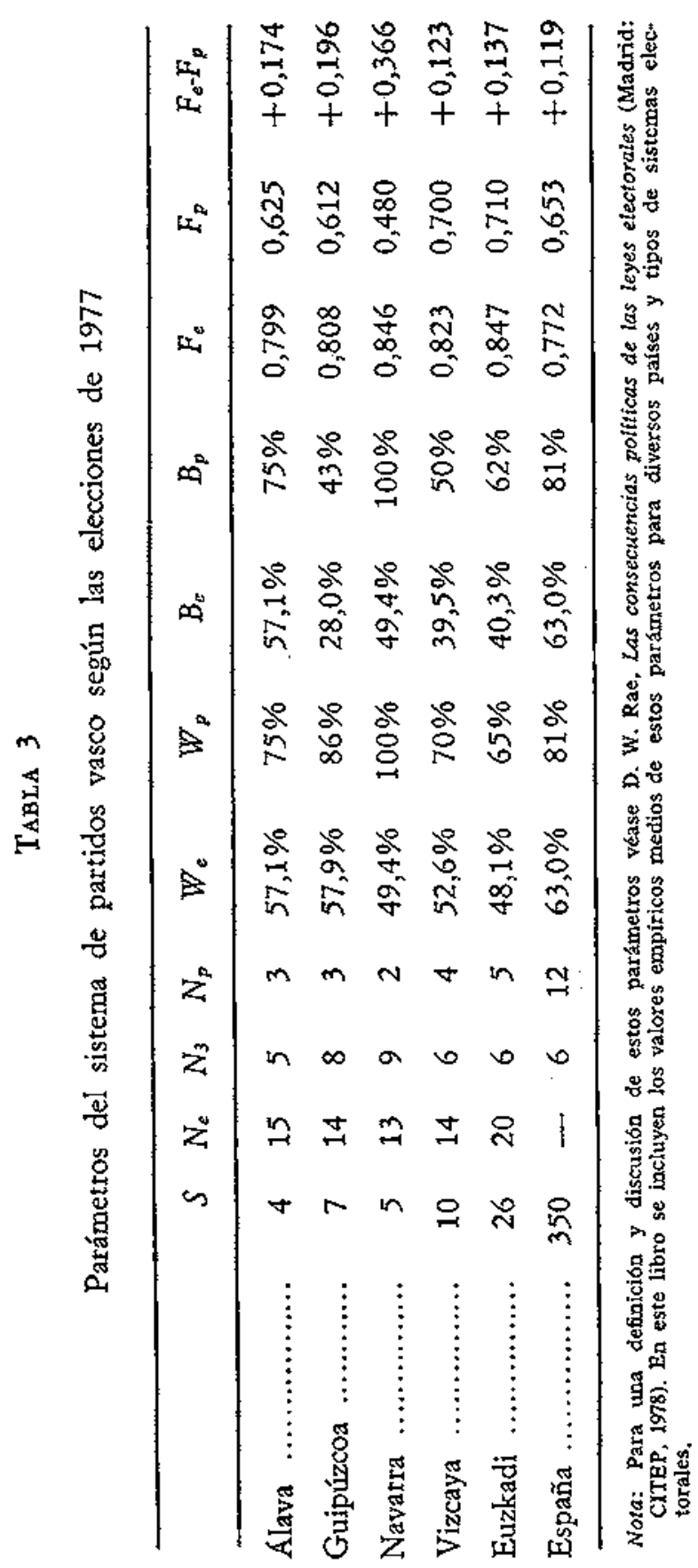


ríodo de configuración, en Euzkadi aparece un sistema de partidos que presenta índices mucho mayores de volatilidad o fuidez, y cuyos principales parámetros se exponen a continuación.

\section{Parámetros y principales fuerzas del sistema de partidos}

En la Tabla 3 se presentan algunos de los parámetros que pueden usarse para tipificar un sistema de partidos políticos. Estos parámetros se refieren a las elecciones de 1977 , y se presentan para cada una de las cuatro provincias, para toda Euzkadi, y, como tefexencia, para el conjunto de España. Los parámetros que se incluyen en la Tabla 3 son:

1. El nímero de escaños: $S$.

2. El númeto de participantes en la elección: $N_{\text {e }}$.

3. El número de partidos que supera el $3 \%$ de los votos: $\mathbf{N}_{3}$.

4. El número de partidos que consiguen algún escaño: $\mathrm{N}_{\mathrm{p}}$.

5. El porcentaje de los votos obtenidos por los dos primeros partidos: $W_{\mathrm{e}}$.

6. El porcentaje de escaños obtenido por los dos primeros partidos: $\mathrm{W}_{\mathrm{p}}$.

7. El porcentaje de votos obtenidos por el PSOE y la UCD: $B_{e}$.

8. El porcentaje de escaños obtenidos pot el PSOE y la UCD: $B_{p}$.

9. La fraccionalización electoral: $F_{e}$.

10. La fraccionalización parlamentaria: $F_{p}$.

11. La diferencia: $\left(F_{e}-F_{p}\right) .^{15}$

Los 26 escaños que, de acuerdo con la ley electoral usada en 1977 y 1979, corresponden a Euzkadi, no se distribuyer provincialmente con criterios proporcionales a la población, o, menos aún, al censo electoral. Álava es la provincia más sobrertepresentada, pues elige un diputado por cada 38.270 electores. La cifra correspondiente para Vizcaya, la provincia más perjudicada en el reparto, es de 74.957 electores. Éste es un problema no específico de Euzkadi, sino general de la ley electoral en cuestión.

Comparando las columnas $\mathrm{E}$ con $\mathrm{N}_{e}$ se observa que en las provincias vascas el número de partidos o coaliciones electorales es siempre notable-

15. Todos estos parárnetros son los introducidos por D. W. Rae en Las consecuencias politicas de las leyes electorales (Madrid: CITEP, 1978), para caracterizat estáticamente a un sistema de partidos dado. La única novedad es la consideración de $\mathrm{N}_{3}$, pues la ley electoral lleva una barrera del $3 \%$ para poder obtener escaños. Salvo en Madrid y Barcelona, los porcentajes de exclusión del sistema Hondt son superiores al $3 \%$. La diferencia $\left(F_{t}-F_{p}\right)$, que mide el efecto desfraccionalizador, es similar a la diferencia entre porcentajes de votos y escafios para los dos primeros partidos, que también podría usarse. 
mente superior al número de escaños a tepartir. En este sentido Euzkadi y Cataluña suelen ser casos atípicos, ya que en ellas opera la doble polatización izquierda/derecha y nacionalismo/no nacionalismo, lo que resulta en una proliferación de partidos. En general varios de ellos son partidos con cierta fuezza electoral, como lo demuestra el que, en todas las provincias de Euzkadi, el número de partidos $N_{3}$ que consiguen superar la barrera del $3 \%$-que es la barreta mínima legal para poder obtener escaños- es siempre superior a 5 , en el caso de Guipúzcoa llega a 8 , y en el de Navarra a 9, a pesar de que en esta provincia hay sólo 5 escaños para repartir. Sin embargo, el número de partidos $\mathrm{N}_{\mathrm{p}}$ que obtienen escaños es, a nivel provincial, sensiblemente infetior a $\mathrm{N}_{3}$. Los valores para los casos extremos de Navarra y Guipúzcoa son 2 y 3, respectivanente. Este fenómeno es debido básicamente a la manera en que la fórmula electoral de Hondt opera sobre distritos que, como los vascos, son de magnitud pequeña o media, y en los cuales compiten un gran número de partidos. Para Euzkadi este efecto se refleja en el dato de que sólo 5 de las 20 fuetzas políticas contendientes obtienen algún escafio.

El grado de bipartidistro existente en las provincias vascas viene medido por $W_{e}$. Los porcentajes están, a nivel de votos, muy alejados del criterio que D. Rae utiliza para definir un sistema como bipartidista, a saber, que los dos primeros partidos alcancen un $90 \%$ del electorado, y que ninguno de ellos llegue por sí sólo al $80 \%$, condición ésta no alcanzada en ninguna provincia española. El hecho de que los dos primeros partidos no sean siempre los mismos en cada una de las cuatro provincias, hace que el valor de $W_{e}$ para toda Euzkadi sea menor que para cualquier provincia. En ninguna de ellas se Ilega al índice de bipartidismo español, que es el $63 \%$. La tendencia al bipartidismo, esto es, a porcentajes de los dos primeros partidos del orden del $90 \%$, aparece si del índice de votos W. pasamos al de escaños $W_{p}$. En el caso de Navarra, los dos primeros partidos obtienen todos los escaños en litigio. Sin embargo, y por la razón anteriormente apuntada, el valor de $W_{p}$ para Euzkadi es también relativamente bajo, 16 puntos inferior al correspondiente a España. Los porcentajes correspondientes a los dos primetos partidos estatales, $\mathrm{B}_{\mathrm{c}}$ y $\mathrm{B}_{\mathrm{p}}$, coinciden con los valores de $\mathrm{W}_{e}$ y $\mathrm{W}_{\mathrm{p}}$ en Alava y Navarra, pero no en las provincias costeras ni en el conjunto de Euzkadi. La sociedad vasca, menos aún que la sociedad española, no responde a un esquema bipartidista, si bien la ley electoral ejerce fuertes presiones en esa dirección. Los dos primeros partidos obtienen siempre un importante exceso en el porcentaje de escaños sobre el de votos. Para las provincias vascas este exceso oscila entre un $50,5 \%$ en Navarra a un $17,4 \%$ en Vizcaya. Para Euzkadi este exceso es de un $16,9 \%$, y para España de un $18 \%$. 
La fraccionalización electozal $F_{c}$ mide el grado de multipartidismo electoral, y de acuerdo a los estudios de D. Rae, suele ser una función de la magnitud de los distritos, es decir, del número de escaños $\mathrm{S}$ de los mismos. Para las provincias vascas esta norma se cumple, excepto en la clara excepción de Navarra, que con una magnitud de 5: presenta la mayor fraccionalización electorai, con un valor de 0,846 . Esto es debido a que, de los 15 partidos y coaliciones que compiten en Navarra, todos menos la LKI superan el $2 \%$, y todos salvo cinco sobrepasan el $4 \%$. Por otra parte los primeros partidos son relativamente débiles, pues la UCD obtiene sólo el $28,52 \%$, y el PSOE el 20,7 \%. El hecho de que los partidos pequeños sean relativamente fuertes, y los grandes relativamente debiles, es lo que explica el elevado valor navaro de $F_{e}$. En una perspectiva comparada, los valores de $F_{e}$ para las provincias vascas se sitúan claramente por encima de la media nacional y del resto de las provincias españolas, salvo las catalanas, en las que se obtienen valores similares. ${ }^{16}$ Para hacerse una idea del grado de fraccionalización del Pás Vasco se puede citar que el valor medio de $F_{c}$ para Israel durante el período 1945-1965, fue de 0,81 . Istael tiene una ley electoral según la cual todo el país es un único distrito, y sólo es preciso superar el $1 \%$ de los votos para poder estar representado en el Parlamento. Estos rasgos han potenciado altamente el multipartidismo y la fraccionalización electoral judía. En las provincias vascas, con un sistema electoral mucho más desfraccionalizador, se obtienen valores de $F_{e}$ similates o supetiotes a los israelitas.

Los valores de $F_{p}$, como es lógico, resultan sustancialmente inferiores a los de $F_{c}$. La diferencia $F_{e}-F_{p}$ es siempre positiva, lo cual por otra parte sucede en cualquiera de las provincias españolas. Esta diferencia se sitúa para las provincias vascas claramente por encirna de la media española. El caso vasco extremo corresponde también a Nalvarra, en donde la diferencia entre los dos índices, la cual puede tomarse como una medida del efecto desfraccionalizador de la ley electoral, alcanza un valor de 0,366 . Navarra, como se ha citado, presenta el hecho insólito de que los dos primeros partidos, sin alcanzar el $50,0 \%$ de los votos obtienen el $100 \%$ de los escaños. La desfraccionalización es también fuerte en Guipúzcoa, en donde los siete escaños se reparten entre sólo tres partidos: tres a PNV, tres a PSOE, y uno a EE. El efecto desfraccionalizador es mínimo en Vizcaya, ya que con diez escaños comienzan a notarse tendencias hacia la pro porcionalidad, incluso con el sistema de Hondt. Aunque Alava tiene la

16. Los valores de $F_{\epsilon}$ para las provincias catalanas son: Barcelona, 0,817; Gerona, 0,820; Lérida, 0,832; y Tarragona, 0,817 . En la otra nacionalidad hístórica, Galicia, Ios valores son más bajos: La Coruña, 0,722; I 19n. 0,679; Orense, 0,597; Pontevedra, 0,652 . Estos valotes, sin embargo, es posible que jayan aumentado significativa- 
menor magnitud, y podría por tanto esperarse allí un máximo valor de $\left(\mathrm{F}_{\mathrm{t}}-\mathrm{F}_{\mathrm{p}}\right)$ esto no es así, ya que en Álava los tres primeros partidos (UCD, PSOE, PNV), tienen una fuerza no demasiado disimilar, y los siguientes partidos aparecen ya muy lejos de ellos. Los tres obtienen escaños, y el sistema de Hondt sólo influye para premiar al primero de ellos (UCD) al que le da dos de los cuatro escaños, a costa de perjudicar en mayor o menor medida a todos los demás partidos.

Es interesante apuntar que en las elecciones de 1979 los efectos desfraccionalizadores de la ley electoral -idéntica a la de 1977- no han sido tan acusados en algunas provincias, debido a la nueva distribución del voto en las mismas. En todas las provincias salvo Alava (en la que la distribución de escaños ha sido idéntica a la de 1977) los valores de $F_{p}$ han aumentado. El aumento ba sido máximo en Guipúzcoa, donde se ha pasado del 0,612 al 0,776. En esta provincia la distribución de escaños es ahora mucho más pluralista: 2 PNV, 2 PSOE, $1 \mathrm{HB}, 1 \mathrm{UCD}, 1 \mathrm{EE}$. El valor de $F_{p}$ también ha aumentado en Navarra, en donde pasa al 0,560. En esta provincia uno de los escaños del PSOE ha pasado a UPN, mientras que UCD mantiene los tres que tenía. En Vizcaya el incremento de $F_{p}$ ha sido más moderado, ya que el valor de 1977 era ya relativamente aito. El actual valor es de 0,720 .

En el Gráfico 1 se han representado en un espacio bidimensional las doce fuerzas políticas más importantes que fueton cuajando en Euzkadi durante 1978 y compitieron en las elecciones de 1979. El eje horizontal de este gráfico corresponde a la dimensión derecha/izquierda, y el eje vertical a la dimensión nacionalismo vasco (hacia arriba)/nacionalismo español (hacia abajo). ${ }^{\text {t7 }}$

Con respecto a las fuerzas políticas representadas son precisas las siguientes matizaciones: a) Los votos de la coalición NV que forman en Navarra el PNV, EE y el PTE se han adjudicado al primero de estos partidos. b) En el caso de UFV se incluyen los votos obtenidos en Navarra por UPN.

En el Gráfico 1 es preciso distinguir los aspectos objetivos de los subjetivos. Entre los primeros están los dos siguientes: a) El área de Ios

mente en 1979 , mientras que los catalanes y vascos o se han estabilizado o han tenido aumentos moderados.

17. Las ideas para la confección del Gráfico 1 están sugeridas por el tratamiento que $G$. Sartori hace del sistema de partidos italiano en el clásico artículo Europeans political parties: The case of polarized pluralism, en M. Binder y J. LaPalombara, comps., Political parties and political development (Princeton: Princeton University Press, 1966). Las ideas generales de G. Sartori sobre sistemas de partidos aparecea recogidas en Party Systems (Cambridge: Cambridge University Press, 1975). 


\section{Gráfico 1}

Representación bidimensional del sistema de partidos vasco en 1979

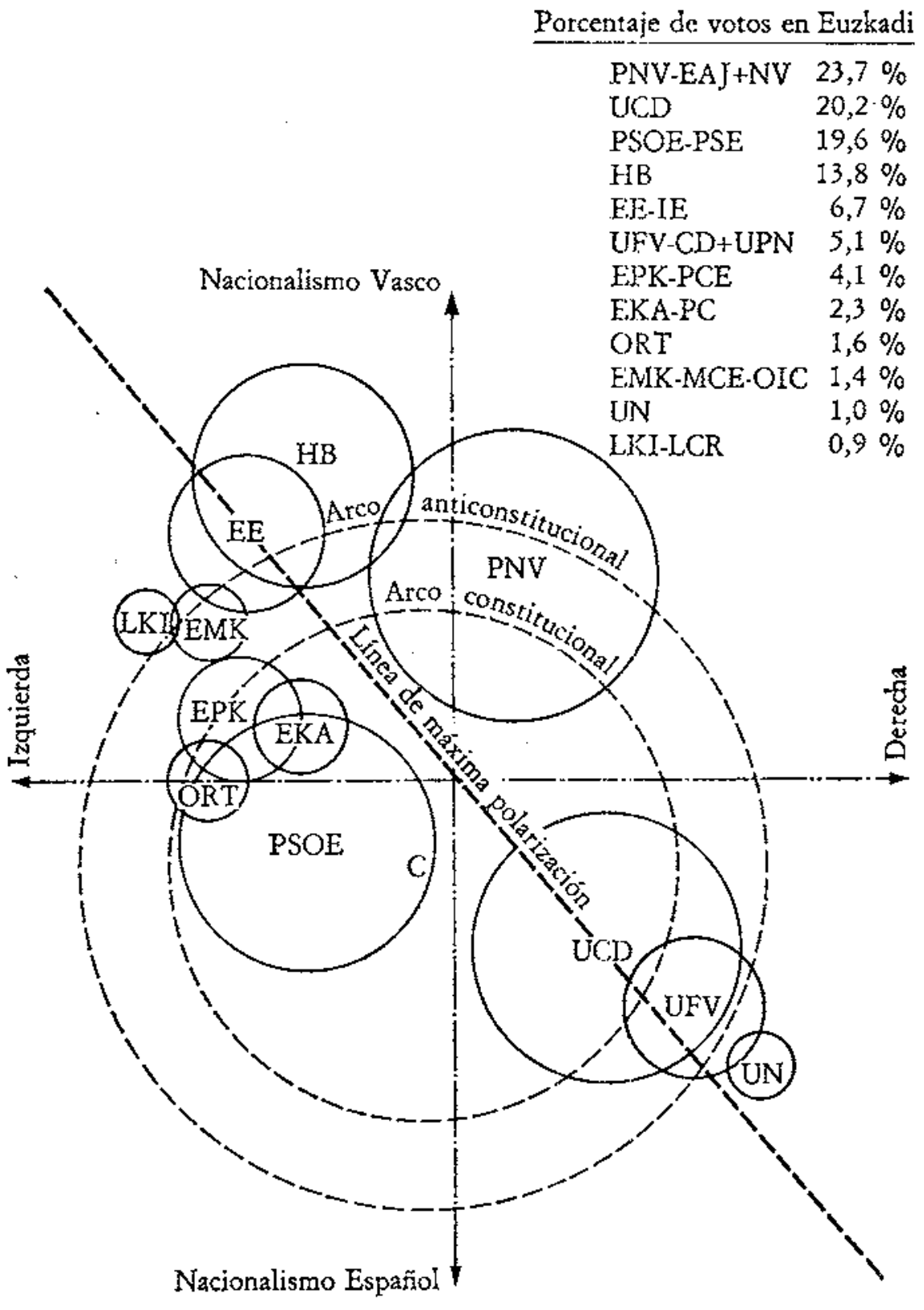


círculos alrededor de las siglas de cada partido o coalición es proporcional al porcentaje de votos obtenido en Euzkadi en 1979. b) Las siglas de cada partido quedan dentro del «arco constitucional», fuera del «arco anticonstitucional", o entre ambos, en función de la actitud que adoptaton ante el referéndum del 6 de diciembre. Dentro del primer arco quedan las siglas de los partidos que recomendaron el voto afirmativo; fuera del segundo quedan las de los que apoyaron el voto negativo, y entre ambos quedan las de los partidos que apoyaron la abstención (PNV, EMK) $\circ$ adoptaron actitudes ambiguas o contradictorias ante la votación (caso de AP luego transformada en UFV-CD).

Prescindiendo de lo anterior todo el resto del Gráfico 1 tiene el carácter de bipótesis plausible. En particular la crucial ubicación de cada fuerza política en este plano bidimensional responde en medida importante a criterios subjetivos. Una manera de Ilevarla a cabo más objetiva. mente sería por medio de encuestas en las que la población ubicase a los partidos en cada una de las dos dimensiones. ${ }^{18}$

Con las salvedades anteriores el Grático 1 sirve para poner de manifuesto que el sistema de partidos políticos que actualmente se confgura en Euzkadi es un sistema cuadripolar. Los cuatro polos del mismo pertenecen a cada uno de los cuatro bloques estudiados anteriormente. UCD es el polo de la derecha española, el PNV de la derecha nacionalista, el PSOE de la izquierda no nacionalista, y $\mathrm{HB}$ de la izquierda abertzale.

En el átea de detecha española además de UCD aparecen las fuerzas UFV y UN. Lo peculiar de ambas es que compiten con UCD desde la periferia del arco constitucional. De acuerdo con la terminología de Sartori, UFV y especialmente UN (ha cual es una fuerza nítidamente anticonstitucional), tienden a ejercer e imprimen al sistema un carácter centrif́fugo, oponiéndose a las tendencias centrípetas.

Como se ha mencionado, el PNV es el polo y la única fuerza de la derecha nacionalista. Lo peculiar del PNV es que, siendo un partido que en la dimensión izquierda/derecha suele tender hacia el centro, y así lo refleja su ubicación, sin embargo, su enfoque de la problemática nacional vasca le sitúa fuera del arco constitucional. Aunque el PNV no tiene com-

18. Este tipo de estudios de autoclasificación se ha llevado ya a cabo para $\propto$ cho paises europeos y americanos (USA, Reino Unido, Alemania Federal, Suiza, Holanda, Austria, Finlandia e Italia) por G. Sartori en Polarization, fragmentation, and competition in Western democracies, IX Congteso Mundial de Sociología (Upsala, 1978). Lo interesante en Esparia setía el complementar las encuestas con autoclasificaciones en el eje vertical de nacionalismo. Un trabajo aś se está llevando a cabo en Cataluña por un equipo de investígadores de la Universidad de Barcelona dirigidos por Carlota Solé. 
petidores directos dentro de su área, sin embargo, no está libre de competencia, pues los planteamientos populistas de $\mathrm{HB}$ han tenido eco entre cierta parte de su electorado. Este efecto de $\mathrm{HB}$ sobte el PNV es similar al que ejercía UFV y UN sobre UCD. Ambos tienden a acentuar el carácter centrífugo del sistema. La competencia de EE sobre el PNV es sin duda menor por el marcado carácter marxista tevolucionario de EE. ${ }^{19}$

En el bloque de la izquierda no nacionalista se pueden distinguir los partidos que, al igual que el PSOE, están dentro del arco constitucional y compiten con é (casos del PCE-EPK, el PC-EKA, y la ORT) de aquellos partidos situados fuera de este arco, y cuyo planteamiento es el de tratar de servir de puente o lograt una síntesis entre la izquierda no nacionalista y la izquierda abertzale. Éste es el caso del EMK-OIC, situado entre los dos arcos, o de la LCR-LKI, que pot sus planteamientos obreristas-a-uitranza se opuso decididamente a una constitución de consenso interclasista.

El polo $\mathrm{HB}$ es, de acuerdo a los resultados electorales de 1979, el menos fuerte de los cuatro. Sin embargo, no lo sería en el caso de que se sumaran los resultados de $\mathrm{HB}$ y EE. Este polo es uno de los que imprimen mayor carácter centrífugo y polarizante al sistema, tirando continuamente hacia arriba y hacia la izquierda de los partidos de los bloques de izquierda no nacionalista y del PNV. La relativa debilidad electoral del bloque de izquierda abertzale se compensa con creces con su inherente dinamismo interno, su emergencia expansiva, su mayor implantación en la juventud, su capacidad de movilización de masas, y su decidida y continua lucha por el control de la calle.

El sistema de partidos vasco está altamente polarizado, porque las distancias en el clásico eje derecha/izquierda se ven incrementadas por la polarización en torno a la cuestión nacional vasca. Intuitivamente se puede afirmar que la distancia que puede existir entre los polos de HB y UCD es mucho mayor que la que pueda existir entre cualquier partido comunista y democristiano o conservador del sur de Europa, que es el caso que se suele tomar para tipificar, según G. Sartori, un sistema como altamente polarizado.

Otra característica del sistema de partidos vasco es que, en general, los pequeños y medianos partidos no ocupan posiciones intermedias entre los polos, con lo cual las posibilidades de mediación y compromiso interpolar que se dan en otros sistemas como el italiano (en el que se pueder considerar como partidos interpolares aI PRI, PSDI, e incluso al mismo

19. EE tiene, por ejempio, un coeficiente de cortelación negativo con el PNV en Vizcaya, mientras que con otros partidos de izquierda es positivo. La presencia del antiguo dirigente del PNV, Telesforo Monzón, en las filas de HB es una muestra explícita de la competición, limitada pero importante, existente entre ambas fuerzas. 
PSI) o incluso el catalán (donde están los casos de CDC o ERC) no están disponibles en la política vasca. Los tres polos de los bloques históricos no tienen ninguna fuerza intermedia entre los mismos. Por otra parte la distancia entre ellos sigue siendo grande, y adetnás sus respectivos electorados tienden a ser excluyentes. Esta hipótesis se ha materializado en el Gráfico 1 de forma que los círculos de la UCD, el PSOE, y el PNV no sean ni secantes ni tangentes.

Los partidos intermedios de la izquierda no nacionalista y con vocación mediadora (éste ha podido ser el caso del PCE-EPK que ha tratado sin éxito de aminorar las distancias entre el PNV, el PSOE y la UCD) han visto dificultados sus propósitos, por ser partidos sin tepresentación en el Parlamento español, y haberse confgurado las instituciones oficiales de la vida política vasca democrática (Asamblea de Parlamentarios, CGV) en base a los resuitados de las elecciones generales. Ésta ha sido la situación entre junio de 1977 y marzo de 1979 , aunque es posible que cambie algo tras las elecciones locales.

En cualquier caso hay que resaltar que en general la tendencia de los partidos pequeños, tanto de izquierda (LKI, EMK-OIC), como de derechas (UFV-UN) es a incrementar las tendencias centrífugas del sistema a lo largo de la línea de maxima polarización, que vendtía a coincidir con la diagonal del gráfico que va de la parte superior izquierda a la parte inferior derecha.

El sistema de partidos vasco puede, de acuerdo con los resultados de 1979 y la interpretación aquí dada a los mismos, caracterizarse como un sistema cuadripolar, de elevada fragmentación, centrífugo, y con uns fuerte polarización.

\section{Correlaciones entre los polos}

Aunque la mejor evidencia sobre el modelo de partidos propuesto procederá de estudios de clasificación directa de los partidos en las dos escalas propuestas, bien por el electorado, o por sectores del mismo, sin embargo, existen otros tipos de evidencias indirectas que pueden aducirse en apoyo del citado modelo. Entre estas evidencias indirectas están los coeficientes de correlación entre los partidos. Si tal como se ha propuesto, el sistema vasco de partidos está caracterizado por cuatro partidos-polos situados a considerable distancia unos de otros, se puede hipotetizar que los coeficientes de correlación para estos partidos serán negativos.

En la Tabla 4 se presentan los coeficientes de correlación lineal en cada una de las cuatro provincias, para los partidos UCD, PSOE, PNV y ESB. Los coeficientes de correlación se han calculado con los porcentajes 
de votos obtenidos por cada partido en los municipios de la provincia en cuestión. Se han utilizado los datos correspondientes a las elecciones de 1977, extraídos de los listados de ordenador entregados por el Ministerio del Interior, y que pueden considerarse como resultados oficiosos de las elecciones. Se ha incluido al partido ESB, socialdemócrata de la izquierda abertzale, que participó en las elecciones de 1977, y que en las de 1979 ha sido uno de los integrantes de la coalición $\mathrm{HIB}$, ya que esta coalición, que es uno de los cuatro polos del modelo, no participó en las elecciones de 1977. En Guipúzcoa, en donde UCD no presentó candidatura, se han utilizado los porcentajes de votos obtenidos por la IDCV, partido cuyo electorado de 1977 puede haber coincidido en parte con el de UCD en 1979. En Navarra las correlaciones se han hecho con UNAI en vez de con ESB, ya que éste integró en 1977 la coalición UAN, dominada por el PNV. ${ }^{20}$

\section{TABLA 4}

Coeficientes de correlación interpolates en 1977

\begin{tabular}{|c|c|c|c|c|}
\hline & \multicolumn{2}{|c|}{ Provincias costeras } & \multicolumn{2}{|c|}{ Provincias interiores } \\
\hline & Guipúzcoa & Vizcaya & Alava & Navarra \\
\hline UCD - PNV & $-0,66$ & $-0,56$ & $-0,52$ & $-0,28$ \\
\hline UCD - PSOE .. & $+0,36$ & $+0,28$ & $-0,64$ & $-0,26$ \\
\hline UCD - ESB $\ldots$. & $+0,05$ & $-0,08$ & $-0,12$ & $-0,38$ \\
\hline PNV - PSOE $\quad \ldots \ldots \ldots \ldots$ & $-0,66$ & $-0,63$ & $-0,24$ & $-0,33$ \\
\hline PNV - ESB ... & $-0,22$ & $-0,06$ & $+0,30$ & $-0,13$ \\
\hline PSOE - ESB $\ldots \ldots \ldots \ldots \ldots$ & $-0,17$ & $-0,18$ & $-0,21$ & $-0,11$ \\
\hline & $N=81$ & $N=: 96$ & $\mathrm{~N}=51$ & $N=53$ \\
\hline
\end{tabular}

Notas: a) Los coeficientes están calculados con los porcentajes de votos (sobre el total de votos válidos) obtenidos por los partidos a nivel municipai. En Navarra, dado el grą número de municipios, se ha usado una mustra aleatoria de los mismos $(\mathbf{N}=53)$.

b) En Guipúzcoa se usan los porcentajes de DCV en vez de los de UCD, al no haberse presentado este partido en 1977.

c) En Navarra se usan Ios porcentajes de UNAI en vez de los de ESB, por idéatica razon.

20. En el trabajo de L. C. Núñez, Base social de las candidaturas en las elecciones legislativas de 1977 en Guipuzcoa, «Saioak», 12 (1978), se incluyen los coeftcientes de correlación entre la abstención y seis partidos, y entre todos ellos y los datos sobre variables sociológicas incluidos en la cinta del censo provincial usado en aquellas elecciones. Los coeficientes de correlación están calculados a tivel de mesas electorales y, en 
Conviene recordar que los coeficientes de correlación lineal sólo indican, en primera aproximación, la relación existente entre el voto de dos partidos en los distintos municipios de una provincia. Si el coeficiente de correlación es negativo quiere decir que en aquellos municipios en los que el voto por el partido "x» tiende a estar por encima de su media intetmunicipal, el voto por el partido «y» tiende a estar por debajo de su respectiva media, y viceversa. En el caso de que el coeficiente fuese positivo, los porcentajes de voto de ambos partidos tenderían a aumentas o a disminuit pot encima o debajo de sus medias en los mismos municipios. Como el alcance de un coeficiente de correlación lineal es exclusivamente éste, conviene puntualizar que sólo por medio de una inferencia, puede ser tomado como una medida de la «separación» o la «distancia (que en cualquier caso será siempre geográfica) existente entre los electorados de los dos partidos. Es por eso que los coeficientes de correlación se considetan únicamente como una evidencia indirecta en favor del modelo de sistema de partidos."2

Con las salvedades anteriores se puede decir que los resultados de la Tabla 4 muestran unos coeficientes de correlación que en su gran mayoría son negativos. De los 24 coeficientes de correlación que resultan para los cuatto partidos-polos en las cuatro provincias, solamente cuatro no son negativos. De ellos dos corresponden al coeficiente UCD-PSOE en las provincias costeras de Guipúzcoa y Vizcaya. Esta excepción puede ser debida a que en estas provincias, los pequeños y medianos municipios son muy mayoritariamente nacionalistas, y tanto UCD como el PSOE pueden tener concentrados sus votos primordialmente en los centros urbanos y cinturones industriales en los que existen proporciones importantes de inmigrantes que tepartirían sus votos entre estos dos partidos. Si esto fuera así la distancia entre los electorados del PSOE y la UCD quizá fuera menor en estas provincias costeras que la que refleja el Gráfico 1, pudiendo incluso existir alguna zona común de competición entre ambos partidos. Por otra

general, confirman las tendencias de los coeficientes de la Tabla 4, calculados con los porcentajes para municipios. De los coeficientes que coinciden con los aquí presentados, los valores calculados por L. C. Núñez son: PSOE/PNV $=-0,82 ; \mathrm{PSOE} / \mathrm{ESB}=$ $-0,21 ; \mathrm{PNV} / \mathrm{ESB}=0,02$. Algunos de los resultados a los que llega este estudio sugieten que, incluso con el aito nivel de desagregación de datos utilizado, la falacia ecológica puede presentarse. El nivel de desagregación a nivel de mesas es innecesario desde el punto de vista socio-político, pues la división de secciones en mesas se hace exclusivamente en base a critetios de ordenación alfabética de los apellidos de los votantes.

21. Una introducción a la estadística general, y a la teoría de la correlación, puede encontrarse en las series de divulgación universitaria de M. R. Spiegel, Statistics: Schaum's Outline Series (Nueva York: McGraw-Hill, 1961), cap. 14. Existe traducción castellana. 
parte sus coeficientes de correlación para las provincias intetiores son, especialmente en el caso de Álava, claramente negativos.

Otra excepción positiva corresponde al coeficiente de correlación del PNV con ESB en Álava. En esta provincia el voto nacionalista, tal como lo ponen de manifiesto los mapas, suele estar muy concentrado a nivel municipal en los pueblos del norte de la provincia limítrofes con las dos provincias costeras, y esto parece funcionar tanto para el PNV como para ESB. En las otras tres provincias los coeficientes de correlación tienden a ser para estos dos partidos, sobre todo en el caso de Vizcaya, moderadamente negativos.

La última excepción a la tónica general corresponde al caso de UCD (DCV) y ESB en Guipúzcoa, pero el coeficiente de correlación, aunque positivo, es prácticamente cercano a cero. Este fenómeno, así como los bajos coeficientes de correlación entre estos dos partidos en las provincias de Vizcaya y Álava, quizá corresponda a los votos «residuales» que hoy en día puede seguit obteniendo UCD en los antiguos enclaves rurales catlis. tas, en los que habría ciertos porcentajes de electores que continuarían vo. tando - salvando todas las distancias que hay que salvar entre el carlismo y la UCD - derecha y español.

Se puede por tanto afirmar que, al menos en cuanto a Ja distribución geográfica de los bastiones electorales, los electorados de los cuatro partidos-polos tendían, de acuerdo con los resultados de 1977, a estar separados, no existiendo entre los mismos zonas claras e importantes de competición común, que obligarían a los polos a reducir las distancias entre los mismos, y que podrían impulsar tendencias centrípetas en el sistema. Así pues, las características más peculiares del sistema de partidos vascos -polarización, centrifuguismo, fraccionalización-- no solamente pueden cortesponder a la dinámica que los líderes de los partidos imprimen al sistema, sino que existe una base electoral que de alguna maneta también impulsa estas características.

\section{Conclusiones}

En resumen, las conclusiones más importantes que se extraen del presente estudio son las siguientes:

a) A nivel de Euzkadi, y en una perspectiva histórica, se puede afirmar que los tres grandes bloques o tendencias electorales tradicionales ban conservado en los años setenta, y de modo aproximado, la relación de fuerzas que existía entre ellos en los años treinta. Se trata de una relación de fuetzas de aptoximada igualdad. 
b) El hecho más destacado de las elecciones de los años setenta en Euzkadi es la emergencia de un cuarto bloque, de izquierda nacionalista. La emergencia de este cuarto bloque en términos de porcentajes globales de votos se está Ilevando a cabo, en las elecciones legislativas, sobre todo a cargo de los dos bloques de derechas.

c) A nivel provincial las relaciones entre los bloques no son las mismas que al nivel general de Euzkadi. Los partidos nacionalistas, tanto de izquierdas como de derechas, son más fuertes en las dos provincias costeras que en las dos interiores, y en éstas son más fuertes en Álava que en Navarra. La izquierda no nacionalista es la que presenta una distribución provincial más uniforme de sus porcentajes, si bien su distribución intraprovincial es la más heterogénea en cualquiera de ellas.

d) A pesar de los fuertes efectos desfraccionalizadores de la ley electoral, que en Euzkadi tienden a ser máximos por la elevada fragmentación y el relativamente escaso número de escaños, la diferente fuerza de bloques y polos en las cuatro provincias hace que el sistema de partidos de Euzkadi no sea un sistema bipartidista, ni a nivel electoral, ni a nivel parlamentario.

e) Se demuestra que el sistema de partidos vasco actual corresponde a un modelo de tipo cuadripolar altamente fragmentado; y se hipotetiza que se trata también de un sistema centrifugo y de extremada polarización.

f) Una evidencia parcial e indirecta en favor del modelo la proporcionan los coeficientes de correlación lineal para los partidos-polos, calculados a nivel provincial con los porcentajes obtenidos en cada municipio. De los 24 coeficientes sólo cuatro no son negativos, lo que prueba la ausencia relativa de electorados comunes, y por tanto la falta de incentivos en favor de tendencias centrípetas que distinuyesen la polarización.

Las perspectivas a corto y medio plazo para el desarrollo en Euzkadi de una democracia política estable, entendida en el sentido liberal del término, son escasas. En la Euzkadi actual posiblemente no se dan la mayor parte de las condiciones que R. Dahl ha identificado, en base a la experiencia histótica, para la existencia de un régimen democrático, o, en la terminología de este autor, de tipo poliárquico. ${ }^{22} \mathrm{El}$ porcentaje de votos que obtienen en Euzkadi las fuerzas anticonstitucionales es elevado, y además se ve incrementado por el porcentaje también importante que obtienen las

22. R. A. Dahl, Polyarcby: Participation, and Opposition (New Haven: Yale University Press, 1971). También es importante, dentro de una línea de investigación Ligeramente diferente sobre las condiciones necesarias para la democracia política estáble, el trabajo de $\mathrm{H}$. Eckstein, Division and Cobeston in Democracy: A Study of Norway (Princeton: Princeton University Press, 1966), Apéndice B. 
fuerzas semileales a la Constitución, entre las que destaca el PNV. De hecho el porcentaje de votos obtenidos en 1979 por las fuerzas que apoyaton la Constitución de 1978 no llega al $48 \%$ de los mismos, y este porcentaje sería aún inferior si no se incluyese a Navarra. Además hay que resaltar que la distancia política entre estas fuerzas constitucionales, que son la UCD por una parte, y partidos socialistas y comunistas por otra, es demasiado grande como para posibilitar una cooperación decidida entre las mismas. Las posibilidades democráticas aumentarán en la medida en que los actores del sistema vasco tiendan a disminuir las distancias entre los mismos, y viceversa. No es preciso insistir en el papel crucial que puede desempeñar el PNV, según deciỏa moverse hacia el interior del arco constitucional, en cuyo caso existiría una amplia mayoría dentro del mismo, o mo verse hacia afuera del arco anticonstitucional, en cuyo caso es posible predecir que la actual confrontación armada que se está dando entre los polos HB y UCD tenderá a incrementarse. En la línea de teducir distancias también cabe apuntar que los desplazamientos de UCD hacia postuxas más receptivas hacia el nacionalismo vasco son posibles. Cualquier desplazamiento lleva, para el partido que opta hacerlo, asociado el tiesgo de una disminución de su fuerza electoral como efecto de la competencia a la que se ve sometido desde otros partidos. Es fácil intuir que sin estos desplazamientos a partir del sistema actual, la democracia política no será viable en Euzkadi, y por tanto los partidos, y especialmente los que se han 1 la. mado partidos-polos, tendrán que enfrentarse con la disyuntiva entre la participación en la construcción de una Euzkadi democrática en el contexto de la democracia española, en la cual posiblemente vean reducida su implantación electoral actual y no tengan una posición de hegemonía, o bien por otra el mantenimiento de su fuerza electoral a costa de acentuar el carácter centrífugo y polarizado del sistema.

Dado su éxito electoral en 1979, las perspectivas de desplazamientos centrípetos de cualquier tipo por parte de $\mathrm{HB}$ tienen por el momento que descartarse. Con respecto a los otros tres polos, se puede sugerir que los posibles desplazamientos centrípetos serán quizá más factibles a lo largo del eje vertical de nacionalismo, ya que en el horizontal las distancias actuales no son tan grandes, y por otra parte las posiciones relativas son seguramente similares a las que los partidos homólogos, socialistas o de centro-derecha, ocupan en muchos otros países de Europa. Como el PSOE está bastante centrado en el eje de nacionalismo, se puede concluir que, de cara a la democracia o a la confrontación política violenta en Euzkadi, son fundamentalmente el PNV y Ia UCD los que en estos momentos tienen la palabra. 
ApÉNDice. TAbLA DE SIGLAS

Siglas
Castellano Vasco Fuerzas integrantes $\quad$ Ambito electoral
 Ideología dominanie $^{3}$

\section{A. INSTITUCIONES}

Consejo General Vasco

CGV EKN

B. COALICIONES

Euzkadiko Ezquerra

IE $\quad \mathrm{EE}$

Herri Batasuna UP

Koordinadora Abertzale Sozialisia 2

Nacionalistas Vascos ........... NV

Unión Autonomista Navarra, UAN

Unión Navarra de Izquierdas UNAT

C. PARTIDOS

Acción Nacionalista Vasca ... ANV

Alianza Popular' ............... AP

Coalición Democrática '.......

Derechas Autónomas ${ }^{1}$..... CEDA

Convergencia Democrática de

Cataluña ................ CDC

Democtacia Cristiana Vasca. DCV

DCV EKD

Demócratas Independientes

Vascos .......................

Esquetra Republicana de Ca-
taluña ....................... ERC

Euzko Iraultzarako Alderdia

DIV UFA

$\mathrm{EE}$

$\mathrm{HB}$

EAE

1977: PSOE, PNV, Euzkadi: salvo Navarra UCD, EE

1977: EIA, EMK, Ind. Euzkadi: salvo Navarra 1979: EIA, PTE, Ind. Euzkadi: salvo Navarsa 1979: HASI, LAIA. ANV, ESB, Ind. Euzkadi

\section{HASI, LAIA,}

ASK, ETA-m $\quad$ Euzkadi

1979: PNV, EIA, PTE Navarra

1977: PNV, ANV, ESB Navarra

1977: EMK, Indep. Navarta

1979: ORT

Navarra

1977: Guipúzcoa y Vizcaya

1977: Euzkadi salvo Guipúz

1979: AP y oiros

1979: Euzkadi salvo Navarra

España

Cataluña

1977: Guipúzcoa y Vizcaya

1977: Guipúzcoa

2

EIA
Cataluña

Euzkadi en coaliciones
Consenso

Izquierda nacionalista Izquierda nacionalista

Izquierda nacionalista

Izquierda nacionalista Derecha nacionalista Derecha nacionalista

Izquierda nacionalista

Izquierda

Izquierda nacionalista

Derecha española

Derecha española

Derecha española

Centro nacionalista

Derecha nacionalista

Derecha nacionalista

Izquierda nacionalista Izquierda nacionalista 
Herriko A l d e r d i Sozialista
Traultzalea $\ldots \ldots \ldots \ldots \ldots \ldots \ldots$

Trautzzalea .................. Alderdia ....................

Liga Comunista Revoluciona-

ria ...........................

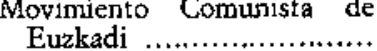

Organización Revolucionaria

de Trabajadores ..............

Partido Carlista ................

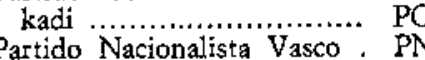

Partido Republicano Italiano PRI

Partido Socíaldemócrata Italiano .......................

Partido Socialista Italiano ....

pañol

partido del Trabajo de Euz-

kadi ..........................

Unión de Centro Democrá.

tico .......................... UCD

Ünión Foral Vasca' ......... UFV

Unión Nacional ................ UN

HASI

LAIA

LCR LKI

MCE-OIC EMK-EKE

ORT $\quad x$

PC EKA

EPK

EAJ

PSDI ?

PSI

PSOE-PSE

PTE

UPN

OTRAS SIGLAS

ASK

Euzkadi ta Askatasuna .........

Gestotas Pro Amnistía
1979: Euzkadi en coalición

1979: Euzkadi en coalición

1979: Euzkadi

1979: Euzkadi

1979: Euzkadi salvo Navarra

1979: Euzkadi

\section{Euzkadi}

Euzkadi salvo Nayarra

Italia

Italia

Italia

Euzkadi

1979: Alava

197\%: CD
1977: Euzkadi salvo Guipúzcoa

1979: Euzkadi

1979: Euzkadi salyo Navarra

1979: Euzkad

1979: Navarra
Izquierda nacionalista

Izquierda nacionalista

Izquierda

Izquierda

Izquierda

Izquierda

Izquierda

Derecha nacionalista

Centro-izquierda

Centro-izquierda

Izquierda

Izquierda

Izquierda

Derecha española

Derecha española

Derecha española

Derecha española

Derecha española

Notas: 1. Formalmente se trata de coaliciones integradas por una serie de partidos de derecha espanola.

2. Se desconoce el uso de siglas en este idioma, aunque en algunos casos pudieran usarse.

3. En caso de no especificgrae el año, el ámbito no varia en las dos elecciones generales consideradas. 